\title{
Evaluation of Pterospermum suberifolium L. Willd Leaves for the Phytochemical Constituents and their in vitro Activities
}

\author{
Research Article
}

\author{
Baskar M1*, Vadamalai Krishnan $\mathrm{K}^{2}$, Muthuraman $\mathrm{K}^{3}$ \\ 1. Associate Professor, 2. Research Scholar, 3. PG Student, \\ PG and Research Department of Botany, Government Arts College for Men (Autonomous), \\ Nandanam, Chennai-600035, Tamil Nadu, India.
}

\begin{abstract}
The present study was intended to investigate the phytochemical constituents present in the leaves of Pterospermum suberifolium L. WILLD and the in vitro antioxidant and antimicrobial properties of the various extracts prepared by different solvents including aqueous, methanol, ethyl acetate and hexane. The crude extracts were screened for the presence of various phytochemical constituents and the presence of phenols, tannins, flavonoids, saponins and alkaloids were ascertained. The quantitative estimation of phenols and flavonoids were determined. The antioxidant activities of the plant leaf extracts were determined by the DPPH assay, the Phosphomolybdenum assay and the Nitric oxide scavenging assay. It was found that methanolic leaf extract of $P$. suberifolium possessed high antioxidant activity and found to have potential phytochemical constituents.
\end{abstract}

Key Words: Phytochemical analysis, antioxidant activity, antimicrobial activity, Pterospermum suberifolium.

\section{Introduction}

Natural products have been an integral part of the ancient traditional medicine systems, e.g. Chinese, Ayurvedic and Egyptian (1). Over the years they have assumed a very central stage in modern civilization as natural source of chemotherapy as well as amongst scientist in search for alternative sources of drugs. About 3.4 billion people in the developing world depend on plant-based traditional medicines. These non-nutrient plant chemical compounds or bioactive components are often referred to as phytochemicals or phytoconstituents and are responsible for protecting the plant against microbial infections or infestations by pests $(2,3,4,5,6)$. The study of natural products on the other hand is called phytochemistry. Phytochemicals have been isolated and characterized from fruits such as grapes and apples, vegetables such as broccoli and onion, spices such as turmeric, beverages such as green tea and red wine, as well as many other sources (5). The science of application of these indigenous or local medicinal remedies including plants for treatment of diseases is currently called ethno pharmacology but the practice dates back since antiquity. Ethnopharmacology has been the mainstay of traditional medicines the

\section{* Corresponding Author:}

\section{Baskar M}

PG and Research Department of Botany,

Government Arts College for Men (Autonomous),

Nandanam,

Chennai-600035, Tamil Nadu, India.

Email Id: captbaskar@gmail.com entire world and currently is being integrated into mainstream medicine. The types of plants and methods of application vary from locality to locality with $80 \%$ of rural dwellers relying on them as means of treating various diseases. For example, the use of bearberry (Arctostaphylosuva-ursi) and cranberry (Vaccinium macrocarpon) juice to treat urinary tract infections is reported in different manuals of phytotherapy, while species such as lemon balm (Melissa officinalis), garlic (Allium sativum) and tree (Melaleuca alternifolia) are described as broad-spectrum antimicrobial agents (7). A single plant may be used for the treatment of various disease conditions depending on the community. Several ailments including fever, asthma, constipation, esophageal cancer and hypertension have been treated with traditional medicinal plants $(8,9)$. The plants are applied in different forms such as poultices, concoctions of different plant mixtures, infusions as teas or tinctures or as component mixtures in porridges and soups administered in different ways including oral, nasal (smoking, snuffing or steaming), topical (lotions, oils or creams), bathing or rectal . Different plant parts and components (roots, leaves, stem barks, flowers or their combinations, essential oils) have been employed in the treatment of infectious pathologies in the respiratory system, urinary tract, gastrointestinal and biliary systems, as well as on the skin $(10,11)$.

\section{Materials and Methods}

Fresh leaves of $P$. suberifolium were collected from the fields located in Ramapuram hills, Tiruvannamalai District, Tamil Nadu. The morphological appearance of $P$. suberifolium is shown in fig. 1 


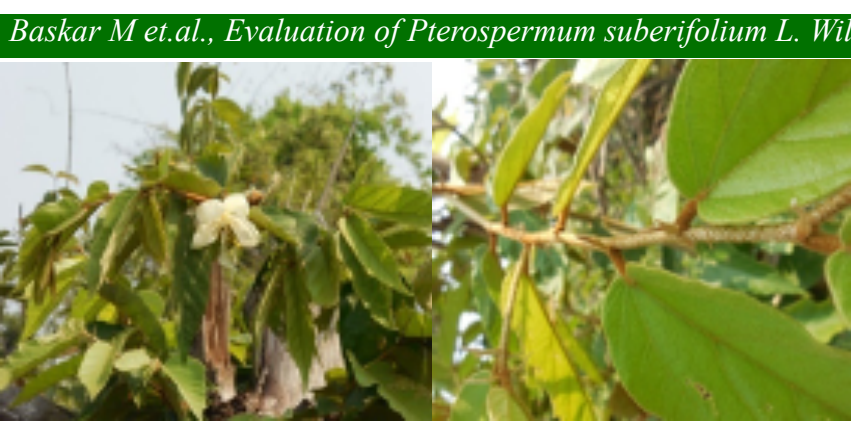

Figure 1: Morphology of $P$. suberifolium Linn.

\section{Preparation of $\boldsymbol{P}$. suberifolium plant extract}

The leaves were carefully washed with tap water, rinsed with distilled water and air-dried for 1 hour at room temperature. Then the leaves were separated and shade dried in room temperature for few days till the leaves were completely dried and able to crush into powder. Then the air dried leaves were ground into powder and subjected to direct extraction with chloroform, ethyl acetate and methanol. The coarsely ground plant material was extracted with chloroform, ethyl acetate and methanol in the ratio of $1: 10(\mathrm{w} / \mathrm{v})$ by repeated extraction. The extract was filtered through the Whatman No. 1 filter paper and the excess solvent was removed by condensation by steam batch (12).

\section{Qualitative phytochemical analysis}

The different qualitative chemical tests were performed for establishing the profile of given extract for its chemical composition. The tests were performed according to the standard methods (13).

\section{Quantitative analysis of phytochemicals}

The total phenols and total flavonoids were estimated using standard techniques (14). A linear correlation has been obtained by comparing the antioxidant activity and polyphenols and flavonoid content of the extracts.

\section{Antimicrobial activity by Well diffusion assay}

The antimicrobial activity was determined for the leaves of $P$. suberifolium against Staphylococcus aureus, Micrococcus luteus, Escherichia coli, Proteus vulgaris, Aspergillus niger and Candida albicans. Tetracycline was preferred as standard reference for antibacterial studies and fluconazole was preferred as standard for antifungal studies.

\section{Antioxidant activity assay DPPH assay}

The Radical Scavenging Activity of different extracts was determined by modified DPPH assay (15). The absorption at $517 \mathrm{~nm}$ of the DPPH solution after the addition of the antioxidant was measured in a cuvette containing $2.96 \mathrm{~mL}$ of ethanolic DPPH $(0.1 \mathrm{mM})$ solution and 20 to $200 \mu \mathrm{g} / \mathrm{ml}$ of Plant leaf extract. The setup was left at dark in room temperature and the absorption was monitored after 20minutes. Ascorbic acid was used as standard. The ability of the plant extract to scavenge DPPH radical was calculated by the following equation:

$\%$ of DPPH Radical Scavenging Activity $(\%$ RSA $)=$ Abs. control - Abs. sample * 100 Abs. control

\section{Phosphomolybdenum assay}

The antioxidant activity of samples was evaluated by the green phosphomolybdenum complex formation (16). An aliquot of $100 \mu \mathrm{l}$ of sample solution was combined with $1 \mathrm{ml}$ of reagent solution $(0.6 \mathrm{M}$ $\mathrm{H}_{2} \mathrm{SO}_{4}, 28 \mathrm{mM}$ Sodium phosphate and $4 \mathrm{mM}$ Ammonium molybdate) and incubated in a water bath at $95^{\circ} \mathrm{C}$ for $90 \mathrm{~min}$. The absorbance of the mixture was measured at $695 \mathrm{~nm}$ against a blank at room teperature. The result was expressed as percentage of inhibition.

\section{$\mathrm{Fe}^{+3}$ Reducing power assay}

The reducing power of the extracts was evaluated according to the standard method prescribed (17). Different amounts of methanol extracts were perched in methanol solvent and diverse with $2.5 \mathrm{ml}$ of $0.2 \mathrm{M}$ phosphate buffer ( $\mathrm{pH} 6.6$ ), and $2.5 \mathrm{ml}$ of $1 \%$ $\mathrm{K}_{3} \mathrm{Fe}(\mathrm{CN})_{6}$. This mixture was incubated at $50^{\circ} \mathrm{C}$ for 20 min, $2.5 \mathrm{ml}$ of $10 \%$ TCA was added to the blend and centrifuged at $3000 \mathrm{rpm}$ for $10 \mathrm{~min}$. The upper layer of the solution $(2.5 \mathrm{ml})$ was assorted with methanol $(2.5$ $\mathrm{ml})$ and $\mathrm{FeCl}_{3}(0.5 \mathrm{ml}, 0.1 \%)$, and the absorbance was measured at $700 \mathrm{~nm}$.

\section{Nitric oxide radical scavenging activity}

Methanolic leaf extract was dissolved in distilled water for quantification of nitric oxide radical scavenging activity (18). Sodium nitroprusside (mM) with standard phosphate buffer saline $(0.025 \mathrm{~m} . \mathrm{h} 7.4)$ was incubated with different concentration (100-400ug/ $\mathrm{ml})$ of methanol extract and tubes were incubated at $29^{\circ} \mathrm{C}$ for 3 hours. Test solution with the equivalent amount of buffer served as control. After $3 \mathrm{hrs}$ incubated samples were diluted with $1 \mathrm{ml}$ of Griess reagent. Ascorbic acid was used as standard and the percentage of free radical scavenging activity was calculated.

\section{Thin Layer Chromatography}

The methanolic leaf extract was loaded on precoated silica plates and chromatography was developed using the solvent system of methanol and chloroform in the ratio of 0.75: 9.25. The seperated spots were visualised both in the UV light $(365 \mathrm{~nm})$ and in the iodine chamber. Then $R_{f}$ value was calculated as the ratio of distance travelled by the solute to the distance travelled by the solvent. 


\section{Result and Discussion}

\section{Qualitative phytochemical analysis}

The phytochemical analysis of hexane, ethyl acetate, methanol and aqueous extracts of $P$. suberifolium showed the presence of flavonoids, terpenoids and phenols in major amounts (Table 1) and was quantified.

Table 1: Phytochemical analysis of $P$. suberifolium leaves of hexane, ethyl acetate, methanol and aqueous extracts

\begin{tabular}{|c|c|c|c|c|c|c|}
\hline \multirow{2}{*}{ S. No. } & \multirow{2}{*}{ Name of the tests } & \multirow{2}{*}{ Phytochemicals } & \multicolumn{4}{|c|}{ Inference } \\
\hline & & & Hexane & Ethyl acetate & Methanol & Aqueous \\
\hline 1 & Mayer's test & Alkaloids & - & - & + & + \\
\hline 2 & Borntrager's test & Glycosides & + & - & + & + \\
\hline 3 & Ruthmann test & Proteins & - & - & - & - \\
\hline 4 & Mace test & Tannins & + & + & + & + \\
\hline 5 & Foam test & Saponins & - & $\ldots$ & + & + \\
\hline 6 & Salkowski test & Terpenoids & + & + & - & + \\
\hline 7 & $\begin{array}{c}\text { Trease and Evans } \\
\text { test }\end{array}$ & Flavonoids & + & + & + & + \\
\hline 8 & Fehling test & Reducing sugars & - & - & - & + \\
\hline 9 & Ferric chloride test & Phenols & - & + & + & + \\
\hline
\end{tabular}

\section{Quantitative analysis}

Quantitative analysis showed that the leaves of $P$. suberifolium, contains higher amount of phenols and flavonoids, and were also estimated (Table 2).

Table 2: Total phenols and flavonoid contents of $P$. suberifolium leaves of different solvent extracts

\begin{tabular}{|c|c|c|c|}
\hline \multirow{2}{*}{ S. No } & \multirow{2}{*}{ Solvent extracts } & \multicolumn{2}{|c|}{ Phytochemicals } \\
\cline { 3 - 4 } & & Total phenol content $(\mathrm{mg} / \mathrm{g}$ of GAE) & Total flavonoid content $(\mathrm{mg} / \mathrm{g}$ of QE) \\
\hline $\mathbf{1}$ & Hexane & 4.76 & 260.7 \\
\hline $\mathbf{2}$ & Ethyl acetate & 139.8 & 647.3 \\
\hline $\mathbf{3}$ & Methanol & 413.3 & 347.6 \\
\hline $\mathbf{4}$ & Aqueous & 221.6 & 187.1 \\
\hline
\end{tabular}

Qualitative phytochemical analysis reflects the presence of alkaloids, glycosides, tannins, saponins, flavonoids and phenols in the methanolic extract and the presence of phytoconstituents varied among the other three different extracts such as hexane, ethyl acetate and aqueous extracts. The crude extracts were assessed for antioxidant potential the results obtained showed promising anti-radical activity at $100 \mathrm{ppm}$ concentration. Regarding antimicrobial effects of P. suberifolium the crude extract showed good antifungal and antibacterial effects (19). In the this study, significant results were obtained from four different extracts of leaves of $P$. suberifolium based on the polarity index of the used solvents.

\section{Antimicrobial activity}

The inhibitory activity for the hexane, ethyl acetate, aqueous and methanolic extract was observed after 24 hours of incubation for bacteria and 48 hours for fungi. The zone of inhibition was measured using zone scale and is represented in Table 3.

Table 3: Zone of inhibition for four different extracts of $P$. suberifolium

\begin{tabular}{|c|c|c|c|c|c|c|}
\hline \multirow{3}{*}{ S.No } & \multirow{3}{*}{$\begin{array}{l}\text { Test } \\
\text { pathogens }\end{array}$} & \multicolumn{4}{|c|}{ Zone of inhibition(mm) } & \multirow{3}{*}{$\begin{array}{c}\text { Standard } \\
\text { 30 } \mu \mathrm{g}\end{array}$} \\
\hline & & $250 \mu \mathrm{g}$ & $250 \mu \mathrm{g}$ & $250 \mu \mathrm{g}$ & $250 \mu \mathrm{g}$ & \\
\hline & & Hexane & Ethyl acetate & Methanol & Aqueous & \\
\hline $\mathbf{1}$ & S. aureus & $12 \mathrm{~mm}$ & $11 \mathrm{~mm}$ & $11 \mathrm{~mm}$ & Nil & $18 \mathrm{~mm}$ \\
\hline 2 & M. luteus & $17 \mathrm{~mm}$ & $15 \mathrm{~mm}$ & $19 \mathrm{~mm}$ & $18 \mathrm{~mm}$ & $20 \mathrm{~mm}$ \\
\hline 3 & E. coli & $11 \mathrm{~mm}$ & $13 \mathrm{~mm}$ & $15 \mathrm{~mm}$ & Nil & $14 \mathrm{~mm}$ \\
\hline 4 & P. vulgaris & $13 \mathrm{~mm}$ & Nil & Nil & Nil & $16 \mathrm{~mm}$ \\
\hline 5 & A. niger & Nil & $10 \mathrm{~mm}$ & $13 \mathrm{~mm}$ & $15 \mathrm{~mm}$ & Nil \\
\hline 6 & C.albicans & $11 \mathrm{~mm}$ & $19 \mathrm{~mm}$ & $12 \mathrm{~mm}$ & $22 \mathrm{~mm}$ & Nil \\
\hline
\end{tabular}


Baskar M et.al., Evaluation of Pterospermum suberifolium L. Willd Leaves for the Phytochemical Constituents and their in Vitro Activities

The antibacterial activity of $P$. suberifolium was found to be higher against $M$. luteus for methanolic extract when compared to other extracts inhibiting zone of $19 \mathrm{~mm}$ at concentration of $250 \mu \mathrm{g} / \mathrm{ml}$; whereas, the inhibitory effect was less as observed for $E$. coli at concentration of $250 \mu \mathrm{g} / \mathrm{ml}$ (hexane extract).

Fig.2. Antibacterial activity of four different extracts of $P$. suberifolium

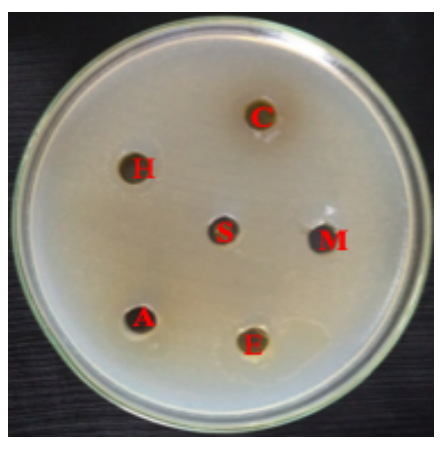

(a) S. aureus

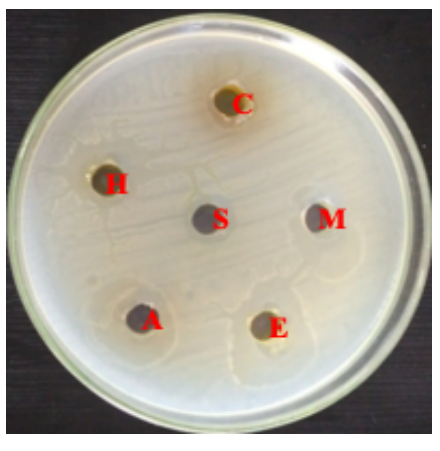

(b) M.luteus

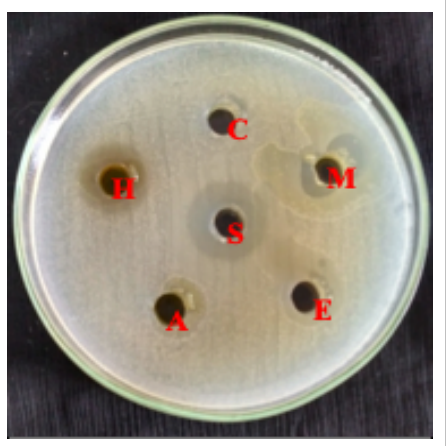

(c) E. coli

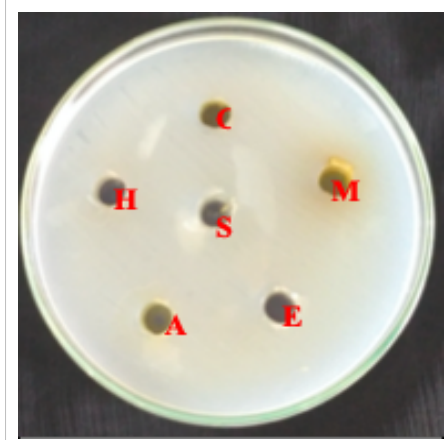

(d) P. vulgaris

Regarding antimicrobial effects of P. suberifolium the crude extract poses good antifungal and bacterial effects. Similarly, the anti-bacterial results were favourable for the crude extracts of $P$. suberifolium. The maximum activity was observed for the methanolic extract exhibiting the zone as $19 \mathrm{~mm}$ against $M$. luteus, when compared to other extracts exhibiting the zone as $18 \mathrm{~mm}$ for aqueous extract, $17 \mathrm{~mm}$ for hexane extract and $15 \mathrm{~mm}$ for ethyl acetate extract. The antibacterial activity was moderately observed for the crude extract against E.coli, P.vulgaris and S.aureus.

Fig.3. Antifungal activity of four different extracts of $P$. suberifolium

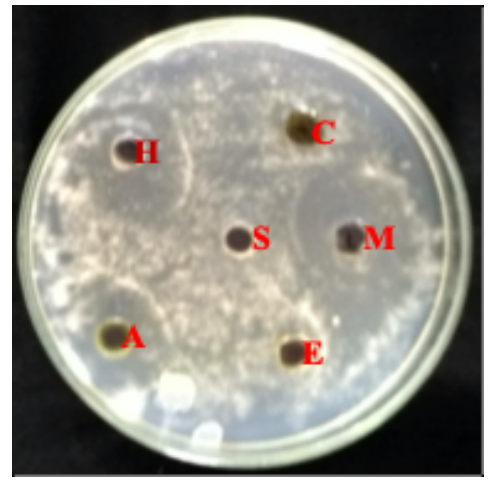

(a) A.niger

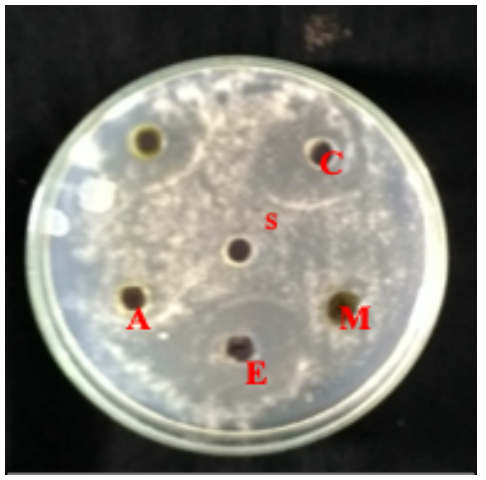

(b) C. albicans

C - Control, H - Hexane extract, EA - Ethyl acetate extract, M - Methanol extract, A- Aqueous extract, S -Standard

The antifungal activity was higher for the crude extract against C.albicans exhibiting the zone as $22 \mathrm{~mm}$ for the aqueous extract at concentration of $250 \mu \mathrm{g} / \mathrm{ml}$. The maximum activity was observed for the aqueous extract exhibiting the zone as $15 \mathrm{~mm}$ against $A$. niger, when compared to other extracts exhibiting the zone as $13 \mathrm{~mm}$ for methanolic extract and $10 \mathrm{~mm}$ for ethyl acetate extract.

\section{In-vitro Antioxidant assay for the leaves of $P$. suberifolium DPPH assay}

The antioxidant activity was carried out by DPPH assay according to the standard method (15). Antioxidant molecules can quench DPPH free radicals (i.e by providing hydrogen atoms or by electron donation, via a free radical attack on the DPPH molecule) and convert them to colourless. The percentage of DPPH scavenging activity was 48.59 in methanol extract of P. suberifolium, 65.38 in aqueous fraction, 48.59 in ethyl acetate extract and 48.067 in hexane extract. 
International Journal of Ayurvedic Medicine, Vol 11 (3), 547-553

Table 4: DPPH Radical scavenging activity for different extracts of $P$. suberifolium

\begin{tabular}{|c|c|c|c|c|c|} 
S. No. & $\begin{array}{c}\text { Concentration } \\
(\boldsymbol{\mu g} / \mathbf{m L})\end{array}$ & Hexane Extract & Ethyl acetate Extract & Methanol Extract & Aqueous Extract \\
\hline $\mathbf{1}$ & 50 & $09.87( \pm 0.69)$ & $19.94( \pm 1.39)$ & $19.94( \pm 0.90)$ & $25.57( \pm 1.789)$ \\
\hline $\mathbf{2}$ & 100 & $27.467( \pm 1.92)$ & $21.22( \pm 1.48)$ & $21.22( \pm 1.91)$ & $36.82( \pm 2.77)$ \\
\hline $\mathbf{3}$ & 150 & $34.337( \pm 2.40)$ & $30.94( \pm 2.16)$ & $30.94( \pm 2.08)$ & $44.24( \pm 3.09)$ \\
\hline $\mathbf{4}$ & 200 & $40.347( \pm 2.82)$ & $35.54( \pm 2.48)$ & $35.54( \pm 2.86)$ & $48.59( \pm 3.40)$ \\
\hline $\mathbf{5}$ & 250 & $44.27( \pm 3.09)$ & $43.74( \pm 3.06)$ & $43.74( \pm 3.33)$ & $57.87( \pm 4.04)$ \\
\hline $\mathbf{6}$ & 300 & $48.067( \pm 3.36)$ & $48.59( \pm 3.40)$ & $48.59( \pm 4.61)$ & $65.38( \pm 4.57)$ \\
\hline
\end{tabular}

Phosphomolybdenum assay

The antioxidant activity was carried out by phosphomolybdenum assay according to the standard method (16). Phosphomolybdenum assay based on the reduction of MO (VI) in to MO (V) by the extract and formation of a MO (V) complex at acidic $\mathrm{pH}$. Increase in Absorbance was observed by standard and extract. The percentage of phosphomolybdenum reduction activity was 0.857 in methanol extract of $P$. suberifolium, 0.997 in aqueous extract, 0.347 in ethyl acetate extract and 0.297 in hexane extract.

Table 5: Phosphomolybdenum Reducing Potential activity for different extracts of $P$. suberifolium

\begin{tabular}{|c|c|c|c|c|c|}
\hline S. No. & $\begin{array}{c}\text { Concentration } \\
(\boldsymbol{\mu g} / \mathbf{m L})\end{array}$ & Hexane Extract & $\begin{array}{c}\text { Athyl acetate } \\
\text { Extract }\end{array}$ & Methanol Extract & Aqueous Extract \\
\hline 1 & 50 & $0.027( \pm 0.001)$ & $0.147( \pm 0.009)$ & $0.017( \pm 0.007)$ & $0.067( \pm 0.004)$ \\
\hline 2 & 100 & $0.097( \pm 0.002)$ & $0.237( \pm 0.001)$ & $0.087( \pm 0.005)$ & $0.127( \pm 0.005)$ \\
\hline 3 & 150 & $0.147( \pm 0.004)$ & $0.267( \pm 0.001)$ & $0.357( \pm 0.002)$ & $0.317( \pm 0.002)$ \\
\hline 4 & 200 & $0.177( \pm 0.003)$ & $0.287( \pm 0.002)$ & $0.487( \pm 0.003)$ & $0.327( \pm 0.004)$ \\
\hline 5 & 250 & $0.227( \pm 0.004)$ & $0.327( \pm 0.003)$ & $0.770( \pm 0.004)$ & $0.987( \pm 0.005)$ \\
\hline 6 & 300 & $0.297( \pm 0.002)$ & $0.347( \pm 0.002)$ & $0.857( \pm 0.003)$ & $0.997( \pm 0.004)$ \\
\hline
\end{tabular}

Ferric Reducing power assay

The inhibition in reducing power assay denotes the yellow colour of the test solution changes to various shades of green and blue depends upon reducing power of each compound. The antioxidant activity of $\mathrm{Fe}^{3+}$ reducing power assay was 0.820 in methanol extract of $P$. suberifolium, 0.790 in aqueous extract, 0.887 in ethyl acetate extract and 1.437 in hexane extract. Antioxidant profile of $P$. suberifolium was evaluated by three methods scavenging of $\mathrm{DPPH}$, total antioxidant assay along with the determination of total phenolic contents. Results revealed that $P$. suberifolium had significant antioxidant DPPH scavenging potential (scavenging $>80 \%$ ) and total antioxidant contents $>0.562$, especially its fruit, stem and bark showed very good antioxidant potential in the same manner, the four different extracts of $P$. suberifolium possessed good antioxidant property which was evaluated by DPPH method $(65.98 \%$ at $300 \mu \mathrm{g} / \mathrm{ml})$, total antioxidant activity, $\mathrm{Fe}^{3+}$ Reducing Potential and Nitric oxide radical scavenging activity $(69.88 \%$ at $600 \mu \mathrm{g} / \mathrm{ml})$.

Table 6: $\mathrm{Fe}^{3+}$ Reducing Potential activity for different extracts of $P$. suberifolium

\begin{tabular}{|c|c|c|c|c|c|}
\hline \multirow[b]{2}{*}{ S. No. } & \multirow{2}{*}{$\begin{array}{c}\text { Concentratio } \\
\mathbf{n} \\
(\mu \mathrm{g} / \mathrm{ml})\end{array}$} & \multicolumn{4}{|c|}{ Absorbance } \\
\hline & & Hexane Extract & $\begin{array}{c}\text { Ethyl acetate } \\
\text { Extract }\end{array}$ & $\begin{array}{c}\text { Methanol } \\
\text { Extract }\end{array}$ & $\begin{array}{c}\text { Aqueous } \\
\text { Extract }\end{array}$ \\
\hline 1 & 50 & $0.487( \pm 0.023)$ & $0.297( \pm 0.014)$ & $0.270( \pm 0.013)$ & $0.417( \pm 0.020)$ \\
\hline 2 & 100 & $0.567( \pm 0.027)$ & $0.377( \pm 0.018)$ & $0.510( \pm 0.021)$ & $0.420( \pm 0.021)$ \\
\hline 3 & 150 & $0.577( \pm 0.028)$ & $0.557( \pm 0.012)$ & $0.590( \pm 0.020)$ & $0.573( \pm 0.028)$ \\
\hline 4 & 200 & $1.270( \pm 0.059)$ & $0.647( \pm 0.031)$ & $0.740( \pm 0.037)$ & $0.660( \pm 0.032)$ \\
\hline 5 & 250 & $1.317( \pm 0.043)$ & $0.667( \pm 0.032)$ & $0.780( \pm 0.026)$ & $0.724( \pm 0.035)$ \\
\hline 6 & 300 & $1.437( \pm 0.064)$ & $0.887( \pm 0.040)$ & $0.820( \pm 0.043)$ & $0.790( \pm 0.039)$ \\
\hline
\end{tabular}

Nitric oxide radical scavenging activity

Nitric oxide is a very unstable species under the aerobic condition. It reacts with $\mathrm{O}$ to produce the stable product nitrates and nitrite through intermediates through $\mathrm{NO}_{2}, \mathrm{~N}_{2} \mathrm{O}_{4}$ and $\mathrm{N}_{3} \mathrm{O}_{4}$. It is estimated by using the Griess reagent. In the presence of test compound, which is a scavenger, the amount of nitrous acid will decrease. The maximum percentage inhibition of Nitric oxide scavenging activity was $63.97 \%$ in methanol extract of $P$. suberifolium, 63.977 in methanol extract, 68.517 in ethyl acetate extract, 69.880 in hexane extract and 51.167 in aqueous extract. 
Table 7: Nitric Oxide radical scavenging activity for different extracts of $P$. suberifolium

\begin{tabular}{|c|c|c|c|c|c|} 
S. No. & $\begin{array}{c}\text { Concentration } \\
(\boldsymbol{\mu g} / \mathbf{m L})\end{array}$ & Hexane Extract & Ethyl acetate Extract & Methanol Extract & Aqueous Extract \\
\hline $\mathbf{1}$ & 50 & $11.771( \pm 0.82)$ & $11.770( \pm 0.81)$ & $19.957( \pm 1.39)$ & $13.267( \pm 0.92)$ \\
$\mathbf{2}$ & 100 & $20.185( \pm 1.41)$ & $37.127( \pm 2.59)$ & $29.687( \pm 2.07)$ & $19.187( \pm 1.34)$ \\
\hline $\mathbf{3}$ & 150 & $36.726( \pm 2.57)$ & $42.367( \pm 2.96)$ & $51.370( \pm 3.59)$ & $24.917( \pm 1.74)$ \\
$\mathbf{4}$ & 200 & $45.560( \pm 3.18)$ & $63.757( \pm 4.46)$ & $51.777( \pm 3.62)$ & $36.157( \pm 2.53)$ \\
$\mathbf{5}$ & 250 & $56.283( \pm 3.93)$ & $65.817( \pm 4.40)$ & $53.367( \pm 3.73)$ & $43.187( \pm 3.02)$ \\
$\mathbf{6}$ & 300 & $69.880( \pm 4.89)$ & $68.517( \pm 4.79)$ & $63.977( \pm 4.47)$ & $51.167( \pm 3.58)$ \\
\hline
\end{tabular}

Antioxidant activity of $P$. suberifolium leaves by nitric oxide radical scavenging activity and reductive ability. Ethanol extracts showed maximum activity when compared to water and acetone extracts. The \% inhibition was $82.74 \mu \mathrm{g} / \mathrm{ml}$ for nitric oxide scavenging activity and $36.15 \mu \mathrm{g} / \mathrm{ml}$ for reducing power. The nitric oxide radical scavenging ability was well observed and the maximum scavenging potential was recorded as 69.88 at $600 \mu \mathrm{g} / \mathrm{ml}$ for hexane extract when compared to other three extracts.

\section{Thin Layer Chromatography}

The leaf extracts of $P$. suberifolium was spotted on pre-coated silica gel plates which were then developed using the solvents Toluene, ethyl acetate and methanol by optimizing the solvent system. The spots were visualised both in the UV light and in the iodine chamber. Then $\mathrm{R}_{\mathrm{f}}$ value was calculated as the ratio of distance travelled by the solute to the distance travelled by the solvent.

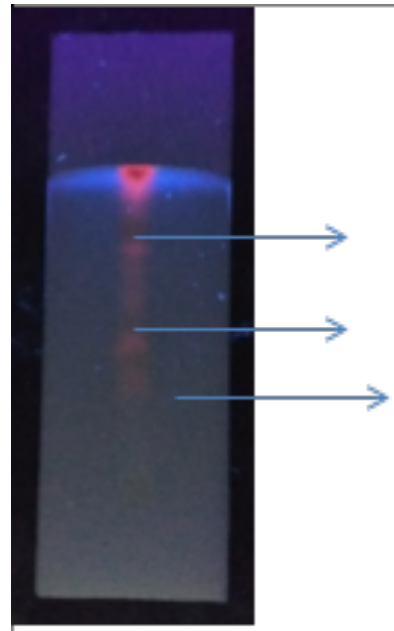

0.93

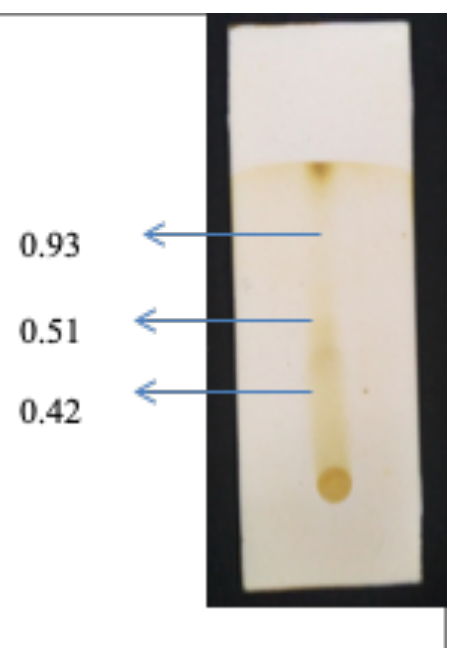

(a) Under Short UV light 365 (nm)

(b) Iodine chamber

Plants contain a wide variety of vital components that are involved in development of new therapeutic agents. Plant tissues are rich source of many phenolic compounds like phenolic acids flavonoids and tannins. These phenolic compounds are radical scavengers and possess antioxidant activity due to their redox properties, hydrogen donor and singlet oxygen quenchers. Phenolic compounds are also responsible for many other biological activities such as anticancer, hepatoprotective, anti-inflammatory and antiatherosclerotic activities. These activities are might be related to their free radical scavenging activity. Flavonoids are the compounds that have ability to reduce the formation of free radicals and scavenging of free radicals. Natural antioxidants present in plants are responsible of inhibiting the oxidative stress. In the present investigation the crude methanol extract of leaves of $P$. suberifolium for free radical scavenging activity by DPPH method. Phytochemical analysis of the selected plant revealed the presence of many important chemical constituents such as glycosides, flavonoids, tannins and terpenoids. Thus the phenolic compounds such as flavonoids that are abundantly present in the leaves of $P$. suberifolium might be responsible for antioxidant potential of this plant.

\section{Summary}

The leaves of $P$. suberifolium were collected from Ramapuram village, Chetpet Taluk, Tiruvannnamalai District. The sample was shade dried and made in to fine powder for further analysis. The fine powder of plant sample was extracted directly with methanol. The preliminary phytochemical screening of the $P$. suberifolium revealed the presence of phenols and flavonoids in high amounts. Alakaloids are present and Glycosides are present. Protein, Terpinoids and redusing sugars are absent. Tanins and Saponins are positive results. Based upon the preliminary phytochemical test, Quantitative determination of phyto constituents was carried out for the extracts of $P$. suberifolium from the standard method. The total phenolic content of methanolic leaf extracts of $P$. suberifolium recorded is $413.3(\mathrm{mg} / \mathrm{g}$ of GAE) respectively and the total flavonoid content of methanolic leaf extracts of $P$. suberifolium recorded as $347.6(\mathrm{mg} / \mathrm{g}$ of $\mathrm{QE}) / \mathrm{gram}$ of quercetin equivalent. The best results of scavenging activity were obtained with a maximum of 48.59 for P. suberifolium at the concentration of $300 \mu \mathrm{g} / \mathrm{ml}$ and the lowest radical scavenging activity recorded in $P$. suberifolium19.94 was when compared with the radical scavenging activity of the standard ascorbic acid by DPPH assay. The percentage of phosphomolybdenum reduction activity was obtained with the maximum 0.857 at the concentration of $300 \mu \mathrm{g} / \mathrm{ml}$ in methanol extract of $P$. suberifolium. The maximum percentage inhibition of Nitric oxide scavenging activity was $63.97 \%$ in methanol extract of $P$. suberifolium. The antioxidant activity of $\mathrm{Fe}^{3+}$ reducing power assay was 0.820 in methanol extract of $P$. suberifolium. The antibacterial activity was observed for the crude extracts of $P$. suberifolium and the maximum activity was observed for the methanolic extract with the inhibition zone of $19 \mathrm{~mm}$. The antifungal activity was higher for the crude extract against $C$. albicans showing the inhibition zone of $22 \mathrm{~mm}$ for the aqueous extract at the concentration of 
$250 \mu \mathrm{g} / \mathrm{ml}$. The maximum antimicrobial activity was observed for the aqueous extract exhibiting the zone as $15 \mathrm{~mm}$ against $A$. niger, when compared to other extracts exhibiting the zone as $13 \mathrm{~mm}$ for methanolic extract and $10 \mathrm{~mm}$ for ethyl acetate extract.

\section{Conclusion}

From the results obtained in this study, it is evident that the methanolic leaf extract of $P$. suberifolium is effective in antioxidant and antimicrobial activities. The TLC developed, suggests that possibly three prospective compounds (when viewed under UV light) in the methanolic leaf extract of $P$. suberifolium which could contribute to its antibacterial activity due to the presence of tannins as one of the phytoconstituents. The antioxidant potentials of the four different extracts were well observed for DPPH activity, phosphomolybdenum potential, ferric reducing potential and nitric oxide radical scavenging property. These results showed that the leaves of $P$. suberifolium could be a potential source of medicine for infections caused by E.coli and S. aureus. Further investigation is necessary to elucidate the exact bioactive compound, responsible for the antiproliferative action.

\section{References}

1. Sarker S.D., Nahar, L. Chemistry for Pharmacy Students General, Organic and Natural Product Chemistry. England: John Wiley and Sons. 2007; 283-359.

2. Abo K.A.,Ogunleye, V.O., Ashidi JS. Antimicrobial poteintial of Spondiasmombin, Croton zambesicus. Journal of Pharmacological Research,1991; 5(13): 494-497.

3. Liu R.H. Potential synergy of phytochemicals in cancer prevention: mechanism of Action. Journal of Nutrition.2004;134(12):3479-3485.

4. Nweze, E.L.; Okafor, J.L., Njoku, O. Antimicrobial Activityies of Methanolic extracts of Trumeguineesis (Scchumn and Thorn) and Morinda lucida used in Nigerian Herbal Medicinal practice. Journal of Biological Research and Biotechnology,2004; 2(1): 34-46.

5. Doughari, J.H.; Human, I.S, Bennade, S., Ndakidemi, P.A. Phytochemicals as chemotherapeutic agents and antioxidants: Possible solution to the control of antibiotic resistant verocytotoxin producing bacteria. Journal of Medicinal Plants Research.,2009; 3(11):839-848.

6. Doughari, J.H., Obidah, J.S. Antibacterial potentials of stem bark extracts of Leptadenia lancifolia some pathogenic bacteria. Pharmacology online 2008;3: 172-180.
7. Heinrich, M.; Barnes, J., Gibbons, S. \& Williamson, E.M. Fundamentals of Pharmacognosy and Phytotherapy. Churchill Livingstone, Edinbrugh, 2004; pp. 245-252.

8. Don cousins Michael and A. Huffman, medicinal properties in the diet of gorillas anethnopharmacological evaluation. African Study Monographs,2002;23(2): 65-89.

9. Santanu Sannigrahi1, SambitParida, V. JagannathPatro, Uma Shankar Mishra, AshishPatha, Antioxidant and Anti-Inflammatory Potential of Pterospermum acerifolium. International Journal of Pharmaceutical Sciences Review and Research, 2010;2(1): 1-5.

10. Rìos, J.L. \& Recio, M.C. Medicinal plants and antimicrobial activity. Journal of Ethnopharmacology.2005; 00: 80-84.

11. Adekunle, A.S. \& Adekunle, O.C.. Preliminary assessment of antimicrobial properties of aqueous extract of plants against infectious diseases. Biology and Medicine. 2009;1(3): 20-24.

12. Harborne J.B General Procedures and Measurement of total phenolics. Methods in Plant Biochemistry 1989; (1); 1-28.

13. Eloff, J.N.. Which extractant should be used for the screening and isolation of antimicrobial components from plants, Journal of Ethnopharmacology, 1998;60, 1-8.

14. McDonald S, Prenzler PD, Autolovich M, Robards $\mathrm{K}$ Phenolic content and antioxidant activity of olive extracts. Food Chem.,2001; 73:73-84.

15. Chang, S.T., Wu, J.H., Wang, S.Y., Kang, P.L . Antioxidant activity of extracts from Acacia confesa bark and heartwood. J.Agric.food Chem.2008; 49: $3420-3424$.

16. Prieto M, Pineda M. Aguilar Anal. Biochem., 1999; (269) 337-341

17. Oyaizu M. Studies on products of browning reactions Antioxidative activities of products of browning reaction prepared from glucosamine. Jap. J. Nutrition, 1986;44: 307-315.

18. LauraC.Green,DavidA.Wagner,JosephGlogowski,P a ulL.SkipperJohnS. Wishnok, Sten and R.Tannenbaum Analysis of nitrate, nitrite, and nitrate in biological fluids Analytical Biochemistry 1982; 126 (1): 131-138.

19. GhiasUddin, SaniaFeroz, Jawad Ali and AbdurRauf. Antioxidant, antimicrobial activity and phytochemical investigation of Pterospermum acerifolium (Leaf petiole). Wudpecker Journal of Agricultural Research 2014; 3(3): 058 - 062. 